\title{
Las dinámicas globales y las nuevas movilidades en el contexto de la expansión del cultivo de soja en la provincia de Santiago del Estero, Argentina
}

\author{
Mariela Blanco y Melina Neiman*
}

\begin{abstract}
Resumen
Los espacios rurales se encuentran subsumidos a las articulaciones sociales, económicas, culturales y ecológicas, inaugurando nuevas regiones sociales. Estas regiones pueden ser analizadas en función de las movilidades que se expresan como un mapa de desplazamientos geográficos, definiendo el perfil de los sujetos sociales que se mueven, la dirección y motivo del traslado y los contextos que se conectan. Estas movilidades incluyen movimientos de capital, de producción por desplazamiento de la frontera agrícola y de población activa.

La provincia de Santiago del Estero, en el norte de Argentina, se ha caracterizado históricamente por la conformación de un importante número de asalariados rurales migrantes que construyen movilidades continuas hacia centros productivos demandantes de mano de obra de tipo temporario, constituyéndose en una de las más importantes dinámicas laborales para la población local. Sin embargo, en los últimos 20 años, parte del territorio provincial ha sufrido diferentes transformaciones como resultado del avance de la frontera agropecuaria, sobre todo a partir de la emergencia de la producción de soja, originando un nuevo paisaje rural así como también cambios económicos y sociales.

En este artículo se presentan los distintos tipos de movilidades que entran en juego en una región transformada por la expansión de la soja: el departamento de General Taboada, en Santiago del Estero. Entre estas movilidades se destaca a) la movilidad empresarial (de los grandes productores sojeros que, tanto de la zona núcleo de la región pampeana argentina como a partir de inversiones internacionales, llegan al departamento); b) la movilidad por expulsión (de los campesinos desalojados de sus tierras) y c) la movilidad laboral (de los trabajadores asalariados que migran en busca de trabajo agrícola por temporada).
\end{abstract}

Palabras clave

Movilidad; Trabajo; Frontera agropecuaria; Región social; Argentina.

\section{TITLE}

Global dynamics and new mobilities in the soybean boom context at the province of Santiago del Estero, Argentina

\section{Abstract}

Rural areas are subsumed to social, economic, cultural and environmental articulations, and incorporate new social regions. These regions can be analyzed in accordance with the mobilities that are expressed as a map of geographical displacements, outlining the profile of the social subjects that move around, the direction and reasons of such movements, and the different contexts that connect them. These mobilities include capital movements, production through the displacement of the agricultural border, and the labour force.

The province of Santiago del Estero, located in the northern part of Argentina, has been characterized historically by the existence of a large number of rural workers who are engaged in continuous migrations to areas in need of temporary workers, situating them in one of the most significant labour dynamics for the local population. However, in the last 20 years, part of the provincial territory has underwent different transformations as a result of the shifting of the agricultural border, mainly after the emergence of soybean production; as a consequence, the local rural landscape has been renewed and socio-economic changes have taken place.

This article concerns the different types of mobilities that appear in a region transformed by the soybean boom; in particular, the General Taboada area in Santiago del Estero province. The following mobilities are identified: a) a corporate based mobility (of large soybean producers, coming to the department from the core area of the widely known Argentinean "Pampas" region as well as from international investors); b) a mobility dealing with population (of peasants evicted from their land), and c) a labor mobility (of workers who migrate looking for seasonal agricultural jobs).

\section{KEYWORDS}

Mobility; Labor; Agricultural frontier; Social region; Argentina.

\section{* Mariela BLAN-} CO, Investigadora Adjunta CEILCONICET. Profesora de la Universidad de Buenos Aires, Facultad de Ciencias Sociales. Dra. Uni-versidad de Buenos Aires, Facultad de Filosofía y Letras, Área Geografía. Mg. en Sociología y Ciencias Políticas, Facultad Latinoame-ricana de Ciencias Sociales (FLACSO), Lic. en Sociología, Universidad de Buenos Aires.

\section{Melina NEI-}

MAN, Investigado-ra Asistente CEILCONICET. Profesora de la Universidad de Buenos Aires, Facultad de Cien-cias Sociales. Dra. Ciencias Sociales, Universidad de Buenos Aires. Mg. en Estudios Sociales Agrarios,

Facultad

\section{Latinoamericana de}

Ciencias Sociales (FLACSO), Lic. en Sociología, Universidad de Buenos Aires.

Ambas autoras comparten el mismo rol protagónico.

Recibido:

2017-04-24

Aceptado:

2017-06-26

DOI: $10.15366 /$

relacionesinternacio nales2017.36.006 


\section{ntroducción}

En el marco del estudio de las movilidades, se señala que el desarrollo del capitalismo y los más recientes procesos de globalización han venido acompañados por una multiplicidad de intercambios tanto de capital y mercancías como de la mano de obra necesaria para llevar a cabo los procesos productivos.

En este artículo, se presenta un análisis de las movilidades en el sureste de la provincia de Santiago del Estero (Argentina) que se ha caracterizado históricamente por la conformación de un importante número de asalariados rurales migrantes que construyen movilidades continuas hacia centros productivos demandantes de mano de obra de tipo temporario; además, en los últimos 20 años, parte del territorio provincial ha sufrido diferentes transformaciones como resultado del avance de la frontera agropecuaria, a partir de la expansión de la producción de soja, originando un nuevo paisaje rural así como también cambios económicos y sociales.

En este contexto, se analiza el proceso de crecimiento de la producción de soja en el departamento de General Taboada, dando cuenta de los diferentes tipos de movilidades que se originan, tanto de población activa como también de producciones y capitales. Para ello, se trabaja con un concepto de movilidad que contempla diferentes formas de moverse en esta región que responden tanto a fenómenos locales como a condiciones externas que impactan sobre el territorio. Entre las movilidades analizadas, se reconoce a) la movilidad empresarial (atraída por los precios relativamente bajos de la tierra combinados con la alta rentabilidad de la actividad agropecuaria); b) la movilidad por expulsión de los campesinos desalojados o relocalizados después de disputas por la tierra originadas en esa expansión y c) la movilidad laboral de los trabajadores asalariados locales que migran hacia otras producciones en busca de trabajo agrícola por temporada.

En el artículo, primero se recuperan los antecedentes conceptuales acerca de las diferentes perspectivas desde las cuales se estudiaron las movilidades tanto en regiones como la nuestra como en otros contextos; posteriormente, se incluye un apartado metodológico en donde se detalla la forma en que se llevó a cabo el proceso de investigación, así como también se describen las características de la zona de estudio. Luego, se presentan los diferentes tipos de movilidad estudiadas, con un análisis acerca de la forma en que se interrelacionan en la región y con el contexto general de incorporación a los mercados internacionales a través de la producción de soja.

Entre los principales hallazgos de este artículo se muestra que la combinación de los múltiples tipos de movilidad conforma determinadas regiones sociales que se ven transformadas por el contexto global de reestructuración productiva aunque, a su vez, dichas movilidades también modifican estos procesos. La forma en que se ven modificados está asociada a los procesos de "reterritorialización", que aparecen como resultado del surgimiento de nuevos perfiles sociales producto de la combinación de movilidades simultáneas.

\section{Antecedentes conceptuales sobre el estudio de las movilidades}

En la actualidad, el estudio de las movilidades reviste una amplia complejidad que comprende a los espacios que las afectan, al tipo de sujeto social involucrado y a los diferentes territorios que se construyen en torno a estos procesos. Hay un acuerdo en entender a los 
movimientos de las personas, antes que nada, como estrategias para acercarse a contextos con oportunidades más favorables ${ }^{1}$. Ahora bien, esas oportunidades más favorables pueden obedecer a desigualdades socioeconómicas de las poblaciones afectadas por la movilidad, a diferenciaciones en la provisión de infraestructura de los espacios o a desequilibrios en el acceso a los recursos.

En la movilidad espacial se constituye un sistema en el que interactúan la movilidad habitual, las migraciones, la movilidad residencial y la estabilidad de la población. Esto permite, a su vez, la delimitación de los contextos geográficos que influyen en los procesos socio-demográficos. Considerar en el interior del entorno espacial inmediato los efectos de la movilidad es fundamental para el análisis socio-espacial ${ }^{2}$. Es decir, se vuelve central dilucidar las conexiones entre el comportamiento de la movilidad y el entorno estable, siendo de vital importancia la delimitación de los contextos a distintas escalas y su grado de influencia ${ }^{3}$. De esta manera, la interacción entre la movilidad y la estabilidad permite integrar distintas escalas de movilidad ${ }^{4}$ y, por lo tanto, de los territorios. La movilidad se puede expresar como una especie de mapa, un registro espacial de desplazamientos, que nos define el perfil de los sujetos sociales que se mueven, la posición en la dirección del traslado y las referencias de los contextos sociales que conecta. Así, podemos estudiar los desplazamientos de trabajadores asalariados hacia mercados de trabajo con condiciones más efectivas de empleo, sobre todo, por las mejores retribuciones al trabajo; con flujos más intensos desde el trabajo hacia el capital y cuyo mapa está limitado por las oportunidades de empleo e ingreso. Los mapas "dibujan la geografía de las ventajas comparativas logradas con respecto al lugar donde se encontraba el migrante"

Los estudios recientes sobre escalas resultan relevantes para comprender los itinerarios de la movilidad. Estos destacan la importancia de visualizar tanto a los constantes movimientos del capital como a sus anclajes espaciales en pos de su reproducción. Por lo tanto, las escalas ya no adquieren un rango de representación en función de un solo elemento diferenciador como podía ser la ciudad, el estado, la nación e inclusive la globalización. Hoy en día el análisis de escalas se orienta a definir, dentro de ciertos límites espaciales, la organización de procesos sociales que adquieren determinada "coherencia estructural" en función de la negociación de objetivos y estrategias de los que participan ${ }^{6}$. La movilidad y la hibridación entre escalas proyectan las relaciones de poder.

Sin embargo, los distintos contextos de la movilidad imprimen a los desplazamientos una serie de propiedades y atributos que escapan a la representación geográfica de los traslados. Los eventos de movilidad se conforman alrededor de lazos y relaciones sociales que

1 DELAUNY, Daniel, "Relaciones entre pobreza, migración y movilidad: dimensiones territorial y contextual" en Notas de Población - CEPAL, No 84, Chile, 2007, pp. 87-130.

2 MÓDENES, Juan, Movilidad espacial: uso temporal del territorio y poblaciones, X Congreso de la Población Española: Migraciones, movilidad y territorio, Pamplona, 29 de junio -1 de julio de 2006: http://www.ced.uab. es/publicacions/PapersPDF/Text311.pdf [Consultado el 11 de abril de 2016].

3 HANSON, Susan, "Perspectives on the geographic stability and mobility of people in cities" en PNAS - Proceedings of the National Academy of Sciences of the United States of America, Vol. 102, No 43, 2005.

4 MÓDENES, Juan, Movilidad..., op.cit., p. 8.

5 DELAUNY, Daniel, "Relaciones..., op.cit., p. 126.

6 GONZÁLEZ, Sara, "La geografía escalar del capitalismo actual" en Pegada, Vol. 6, № 1, 2005, pp. 91-112. 
aparecen como factores de organización de las mismas y suponen mutaciones de los sistemas espaciales (el espacio se estructura por los desplazamientos pero, también, por la circulación de bienes materiales e inmateriales) ${ }^{7}$. Es decir, tras la movilidad se encubren procesos de movilidad muy diferenciados a escala (macro económico, institucional y micro-institucional). Actualmente, la movilidad pone en relación de interdependencia los diferentes territorios de una manera más compleja que antes ${ }^{8}$; es un proceso construido colectivamente en el tiempo por distintas generaciones y cimentado en relaciones sociales, sustentado en una red de saber circular ${ }^{9}$. Se puede considerar como una relación compleja entre procesos sociales y condiciones materiales, que hacen que las territorialidades sean muy dinámicas (cambiantes y flexibles $)^{10}$.

La movilidad territorial permite valorizar las especificidades de los lugares, facilitar la interrelación entre ellos y habilitar los procesos de readecuación. Es así que el territorio es parte del proceso social que se expresa en la migración, interviniendo en función de los objetivos que los actores se fijen desde una estructura determinada por la acumulación de capital ${ }^{11}$.

Para el análisis de la movilidad es importante identificar el grupo social al cual se hace referencia. A veces este colectivo puede ser amplio (el grupo étnico), intermedio (la comunidad o el pueblo) o restringido (la familia); otras veces se puede tratar de un individuo caracterizado por su función o identidad social (campesino, asalariado) ${ }^{12}$.

En determinadas áreas rurales se han observado una serie de cambios sociales a nivel de los hogares (reducción del tamaño, regulación de la natalidad, procesos de individuación en la división del trabajo familiar) que inciden en las estrategias productivas y reproductivas de los mismos y que redundan en los comportamientos de los patrones migratorios ${ }^{13}$. Además, se ha analizado cómo los procesos de descomposición y recomposición de las familias campesinas generan formas novedosas de movilidad y cómo estas movilidades ponen en tensión al interior de estas los elementos de negociación entre las generaciones o, en otros términos, la sobrevivencia de las unidades campesinas ${ }^{14}$.

7 CORTES, Genevieve, "Migraciones, construcciones trasnacionales y prácticas de circulación. Un enfoque desde el territorio" en Párrafos Geográficos, Vol. 8, No 1, 2009, pp. 35-53.

8 QUESNEL, André, "El concepto de archipiélago: una aproximación al estudio de la movilidad de la población y a la construcción de lugares y espacios de vida" en LARA FLORES, Sara (coord.), Migraciones de trabajo y movilidad territorial, Editorial Purrúa, México, 2010, pp. 19-46; LEÓNARD, Eric et.al., "De la comunidad territorial al archipiélago familiar. Movilidad, contractualización de las relaciones intergeneracionales y desarrollo local en el sur del estado de Veracrúz" en Estudios Sociológicos, Vol. 23, No 3, 2004, p. 557.

9 TAURRIUS, Alain, "Las circulaciones migratorias: conveniencia de la noción de territorio circulatorio. Los nuevos hábitos de la identidad" en Relaciones, Vol. 21, No 83, 2000, pp. 38-66.

${ }^{10}$ ALBERTI, Alfonsina et.al., "Temporalidad cíclica y territorio móvil. Los trabajadores forestales del nordeste argentino" en Estudios del Trabajo ASET, No 48, 2014, pp. 5-28.

${ }^{11}$ BLANCO, Mariela y CARRIZO, Lila, "Procesos sociales complejos de interacción e inserción territorial. La mano de obra migrante transitoria en Pomán, Catamarca" en Aportes Científicos para las Humanidades, 2012, p. 1-12.

12 CORTES, Genevieve, "Migraciones..., op.cit., p. 10.

13 QUARANTA, Germán y BLANCO, Mariela, "Formas actuales de circulación y conformación de patrones migratorios de hogares rurales en la provincia de Santiago del Estero, Argentina" en RURIS - Revista do Centro de Estudos Rurais, Vol. 6, No 1, 2012, pp. 127-158.

${ }^{14}$ QUESNEL, André, "El concepto..., op.cit., p. 32. 
También existen procesos de carácter más estructural que se constituyen en canales - espacios de movilidad como pueden ser las políticas económicas, las decisiones de inversión de las empresas o los posibles eventos naturales que desencadenan la movilidad. El asentamiento de empresas conectadas al capital global genera fuertes procesos de movilidad a su alrededor, dando lugar a circuitos de distinta naturaleza en los que intervienen grupos diferentes (locales, migrantes, etc.) y a una alta densidad relacional ${ }^{15}$.

Por lo tanto, para tratar la movilidad es necesario asumir su interdependencia y comprender cómo los individuos combinan diferentes comportamientos de movilidad para cumplir sus fines a corto, mediano o largo plazo ${ }^{16}$.

A partir de lo anteriormente expuesto, este artículo analiza las movilidades que se desarrollan en un espacio en transformación y cómo se compone la interdependencia de las mismas a través de los factores de oportunidades y tensiones que se observan en el territorio, según los diferentes grupos sociales que las componen y transitan.

El caso que se presenta tiene la particularidad de que en su territorio se manifiestan tres tipos distintos de movilidades, con flujos de desplazamientos diferenciados, grupos sociales desiguales y diversas escalas territoriales. Por un lado, se identifica una movilidad laboral circunscripta a un espacio migratorio transitorio, compuesta por el grupo social de trabajadores agrarios que, durante dos meses al año, se movilizan en busca de mejores oportunidades de ingresos hacia otras regiones para realizar la tarea de desflore del maíz ${ }^{17}$. Se denomina laboral porque el desplazamiento se ve alentado por la oportunidad de obtener otros empleos que coadyuven a mejorar los ingresos que obtienen por el trabajo local. Por otro lado, se distingue una movilidad empresarial producto del avance de la frontera agropecuaria, impulsado por cambios en las condiciones ambientales que permiten realizar el cultivo de soja ${ }^{18}$, la alta rentabilidad del cultivo y de un contexto propicio para el acceso a la tierra, aun cuando se presentan situaciones de violencia y conflicto por ese recurso. Las oportunidades de captar la renta por dichas condiciones condujeron a una significativa movilidad de una red empresarial constituida principalmente por empresas proveedoras de servicios. Por último, solapada a la movilidad anterior, se observa una movilidad por expulsión. La competencia por la tierra, como las pocas alternativas productivas para la pequeña producción, suscitó un tipo de movilidad progresiva de los pequeños productores hacia las localidades vecinas o hacia nuevas zonas rurales, generando un proceso de reubicación de parte de la población rural local.

De esta manera, cada movilidad puede representarse como un mapa que caracteriza las distancias entre un origen y destino de los traslados y que opera selectivamente sobre

\footnotetext{
15 LARA FLORES, Sara, "Los territorios migratorios como espacios de articulación de migraciones nacionales e internacionales. Cuatro casos del contexto mexicano" en Política y Sociedad, Vol. 49, N012, 2012, pp. 89-102.

16 MÓDENES, Juan, Movilidad..., op.cit., p.10.

17 La desflorada del maíz consiste en quitar a mano las flores de las plantas hembras que quedarán para semilla, éstas serán polinizadas por las plantas macho. Esta tarea debe ser realizada en tiempo y forma para garantizar la obtención de maíz.

${ }^{18}$ Esta expansión agrícola se realiza en el espacio que comprende la isohieta de $800 \mathrm{~mm}$ (del centro al este de la provincia), que ha sufrido un corrimiento importante en los últimos 15 años producto de los cambios ambientales ocurridos a nivel global; antes se ubicaba casi en el límite este de la provincia (INTA, 2006) y esto ha impactado de manera directa en la introducción de cultivos de cereales y oleaginosas, principalmente la soja.
} 
aquello que transita. Pero la movilidad comprende también los tiempos de la circulación así como las diferentes maneras de circular en función de los arreglos y negociaciones entre las poblaciones que circulan.

Por último, la interrelación de las movilidades se explica a partir de la capacidad que tienen los individuos de entrar y salir de estas, como parte de estrategias individuales de circulación o conformando un colectivo más amplio. De esta manera, el desplazamiento entre movilidades significa aprovechar las ventajas comparativas que ofrecen las mismas.

La movilidad empresarial es la expresión de un modo de capitalismo agrario que se expande desde una región con mayor dinamismo capitalista (en este caso, la región pampeana) hacia regiones con un desarrollo capitalista más lento, constituyéndose en un fenómeno de ocupación, reocupación y reorganización de un territorio ${ }^{19}$. No menos importante ha sido el rol que tuvo el fenómeno de acaparamiento de tierras por parte de capitales foráneos. En Argentina se estima que durante el período 2002-2013 se duplica la cantidad de tierras en manos extranjeras ${ }^{20}$. Si bien en el año 2011 se intentó regularizar el proceso de extranjerización a partir de la sanción de la ley de tierras ${ }^{21}$, se registra que en la región noroeste de Argentina alrededor del $21 \%$ de la adquisición de tierras en manos extranjeras se concretó por medio del apoyo del Estado22. Es importante resaltar que el sistema de acaparamiento se realiza bajo distintas figuras sociales, desde los mecanismos propios del mercado entre privados hasta la venta de tierras fiscales a privados con apoyo de los estados. Diversos estudios se enfocan exclusivamente en el caso de acumulación por desposesión, donde la dimensión explícita de conflicto aparece con más claridad, y se deja así de lado una parte sustancial del fenómeno que ocurre por las "normales" vías del mercado, pero que genera igualmente efectos económicos, políticos y sociales de relevancia ${ }^{23}$. Se trata de empresas de origen extralocal, claramente portadoras de una racionalidad capitalista y que acceden a la tierra a través de la compra o arriendo para desmontarlas y ponerlas en producción ${ }^{24}$.

La acumulación por desposesión forma parte de un tipo de movilidad por expulsión que se expresa en los espacios locales pero que obedece a desplazamientos del capital que ocurren a escala global a partir de la valorización de un recurso, por ejemplo la tierra, en

19 PAZ, Raúl Y JARA, Cristián, "Estructura agraria en Santiago del Estero: el proceso de territorialización de las explotaciones campesinas sin límites definidos y su tensión frente al avance del capitalismo agrario" en Estudios Rurales, No 4, 2014, pp. 81-99.

20 BORRAS, Saturnino et.al., El acaparamiento de tierras en América Latina y el Caribe visto desde una perspectiva internacional más amplia, Borrador, FAO, Roma, 2011: http://www.fao.org/fileadmin/user_upload/rlc/ eventos/229269/borras.pdf [Consultado 11/04/2016].

${ }^{21}$ La ley 26737 limita al 15\% la posibilidad de adquirir tierras a personas físicas y jurídicas extranjeras a nivel nacional, provincial y subprovincial; $30 \%$ de límite a la posesión de personas físicas o jurídicas de la misma nacionalidad en los mencionados niveles; un máximo de 1000 hectáreas en la región pampeana o su equivalente en otras regiones. GORENSTEIN, Silvia y ORTÍZ, Ricardo, "La tierra en disputa. Agricultura, acumulación y territorio en la Argentina reciente" en Revista Latinoamericana de Estudios Rurales, Vol. 1, No 2, 2016, pp. 1-26.

22 COSTANTINO, Agustina, "El capital extranjero y el acaparamiento de tierras: conflictos sociales y acumulación por desposesión en Argentina" en Revista Estudios Sociales, No. 55, enero-marzo, 2016, pp. 137-149.

${ }^{23}$ Ibídem, p. 143.

${ }^{24}$ de DIOS, Rubén y WILLIAMS, Jorge, "Sistemas productivos y organización campesina. El caso de Los Juríes" en ÁLVAREZ, Ramón, Sistemas productivos campesinos en Santiago del Estero. Organizaciones y unidades de producción. Uso de tipologías en los procesos de reconversión, Barco Editó, Santiago del Estero, 1998, p. 191. 
espacios que con anterioridad funcionaban sobre la base de una lógica diferentes ${ }^{25}$. Esta valorización de la producción de la tierra implicó la desposesión de tierras destinadas a fines distintos a la obtención de ganancias (como la reproducción de la familia y la subsistencia de pequeños productores). En Argentina, sobre todo en la región noroeste, muchas familias se encuentran en una situación de tenencia precaria de la tierra, favoreciendo los procesos de exclusión y movilidad, que no sólo presentan una dirección rural-rural, sino también ruralurbana. Las disputas jurídicas por la tierra originaron sucesivos conflictos que, en principio, tuvieron un carácter "silencioso" y que se vuelven "visibles" a partir de los noventa ${ }^{26}$. Luego de sucesivas luchas, los campesinos se organizan y logran, en varias oportunidades, frenar los procesos de desalojo y mejorar la posesión de tierras de las familias reubicadas ${ }^{27}$. Dada las características de los sujetos sociales representados y el reconocimiento de la precariedad en la que se encuentran las producciones campesinas, las reivindicaciones del MOCASE (Movimiento Campesino de Santiago del Estero) se sustentan tanto en cuestiones típicas de asalariados (obra social, jubilación, salario familiar, etc.), como también en aspectos de la producción (cooperativas, asociativismo, entre otras) y, por supuesto, el reclamo por la tenencia de la tierra28.

Por último, la movilidad asociada a los desplazamientos por el trabajo reviste una historia más larga. Este tipo de movilidad se vincula directamente con el traslado de la mano de obra por mejoras contextuales, sobre todo salariales, entre los espacios que unen los desplazamientos. En la actualidad, este tipo de movilidad se halla globalizada, es decir, que cada vez se hace más importante el peso cuantitativo y cualitativo de los movimientos de la población a escala mundial, orientados por el trabajo. El hecho de ser un fenómeno de escala global no significa que sólo contemple los desplazamientos internacionales, sino que estos incrementos se han hecho habituales aun dentro de las fronteras de los países. Hoy en día se evidencia una gran diversificación de rutas y conexiones entre origen y destino ${ }^{29}$.

Las múltiples dimensiones que atraviesan estas movilidades han conducido a que no sólo se atendieran a las dimensiones económicas, sino a cuestiones tales como la diversidad cultural, las etnias, el acceso a las redes sociales, la identidad, el hogar y las familias que han cobrado relevancia en los estudios recientes ${ }^{30}$. Puede decirse que se produce un "cruce de

25 HARVEY, David, "El 'nuevo' imperialismo: acumulación por desposesión" en Socialist register 2004 - CLACSO, Buenos Aires, 2005, pp. 99-129: http://biblioteca.clacso.org.ar/clacso/se/20130702120830/harvey.pdf [Consultado 11/04/2016].

${ }^{26}$ ALFARO, María Inés, "Experiencias de organización campesina en Santiago del Estero. Reflexiones en torno a las acciones colectivas" en BENENCIA Roberto y FLOOD, Carlos (Comp.), ONGs y Estado. Experiencias de organización rural en Argentina, La Colmena, Buenos Aires, 2002, pp. 159-175.

27 BARBETTA, Pablo, "En los bordes de lo jurídico: campesinos y justicia en Santiago del Estero" en Cuadernos de Antropología Social, No 32, 2010, pp. 121-146.

28 DESALVO, María Agustina, "El MOCAASE: orígenes, consolidación y fractura del movimiento campesino de Santiago del Estero" en Astrolabio Nueva Época, No 12, 2014, pp. 271-300.

${ }^{29}$ ARANGO, Joaquín, "La explicación teórica de las migraciones: luz y sombra" en Migración y Desarrollo, № 1 , 2003, pp. 3-31.

${ }^{30}$ SÁNCHEZ SALDAÑA, Kim, "Un enfoque multidimensional sobre los intermediarios laborales en el medio agrícola" en Política y Sociedad, Vol. 49, No 1, 2012, pp. 73-88; PEDREÑO CÁNOVAS, Andrés, Del jornalero agrícola al obrero de las factorías vegetales, M.A.P.A., Madrid, 1999, p. 374; QUESNEL, André, "El concepto..., op.cit., p. 40; LARA FLORES, Sara, Control del espacio y territorialidad en las migraciones rurales. Un empleo en el caso de México, VII Congreso Latinoamericano en Sociología Rural, Quito, 2006; LARA FLORES, Sara, "Los territorios migratorios como espacios de articulación de migraciones nacionales e internacionales. Cuatro casos del contexto mexicano" en Política y Sociedad, Vol. 49, No 12, 2012, pp. 89-102; SEGURA, Pedro et.al., "Configurando la 
escalas" que van de lo internacional a lo local, escalas no sólo geográficas, sino de tiempos y de culturas que se ponen en contacto en estos lugares ${ }^{31}$.

\section{Metodología y zona de estudio}

El trabajo de campo de esta investigación se llevó a cabo desde el municipio Los Juríes que forma parte del departamento de General Taboada, ubicado en el sureste de la provincia de Santiago del Estero. Esta provincia se encuentra dentro de lo que se conoce como "Llanura Chaqueña", en la región noroeste de la Argentina y se caracteriza por la presencia de un relieve muy llano y una tendencia natural a la cobertura forestal.

Santiago del Estero es una provincia que ha atravesado un proceso de incorporación del desarrollo del cultivo de soja en gran parte de su territorio. El incremento de la superficie de soja obedece, en la década de los noventa, al reemplazo de otros cultivos, principalmente porotos, sorgo y maíz. Posteriormente, el incremento se produce por el avance sobre los montes nativos a través de procesos de desmonte ${ }^{32}$.

La renta generada por esta actividad económica tuvo una apropiación fundamentalmente privada ${ }^{33}$, muy concentrada y, en muchos casos, con destino hacia otras regiones y/o países por efectos de la extranjerización de las tierras. A esto se asociaría el aumento en más de un $50 \%$ en la proporción de la superficie de las explotaciones en arrendamiento, entre 1988 y 2002, para el área de estudio. Generalmente, este tipo de contrato es utilizado por grandes empresas agropecuarias no locales, cuya renta es destinada a sus inversores, radicados también fuera de la región y/o país, lo que impediría en parte el desarrollo de las microeconomías regionales ${ }^{34}$.

El aumento en el precio de la soja es lo que motoriza la incorporación de nuevas tierras a la producción en el país, significando un creciente proceso de deforestación incontrolada por el desmonte de extensas superficies que, como tierras vírgenes y feraces, son incorporadas a la producción de la oleaginosa ${ }^{35}$. Las tierras de las áreas sojeras de la provincia de Santiago del Estero poseen valores inferiores cuando se encuentran sin desmontar, pero prácticamente se triplican luego de deforestadas. De todas formas, los valores de los campos desmontados apenas llegan a los límites inferiores de los valores de las tierras agrícolas de la provincia de Buenos Aires ${ }^{36}$.

Región Murciana para las frutas y hortalizas: racionalización productiva, agricultura salarial y nueva estructura social del trabajo jornalero" en Áreas, No 22, 2002, pp. 71-94.

${ }^{31}$ LARA FLORES, Sara, "Los territorios..., op.cit., p. 92.

32 GIANCOLA, Silvana et.al., Análisis de la cadena de soja en la Argentina, Estudios Socioeconómicos de los sistemas Agroalimentarios y Agroindustriales, Estudios Socioeconómicos de los Sistemas Agroalimentarios y Agroindustriales N³, INTA, 2009.

${ }^{33}$ Cabe señalar que en Argentina se aplican políticas de retenciones mediante las cuales el estado participa en parte de la apropiación de la renta de este cultivo. Esta política llevó a importantes conflictos con el sector agropecuario cuya máxima expresión ocurrió en el año 2008.

34 PARUELO, José et.al., Patrones espaciales y temporales de la expansión de Soja en Argentina. Relación con factores socio-económicos y ambientales, Laboratorio de Análisis Regional y Teledetección, Facultad de Agronomía, Universidad de Buenos Aires, 2004.

35 GARCIA, Mabel, La influencia del tipo de productor en la sustentabilidad de los cultivos. El caso de la soja en Santiago del Estero, Tesis de Maestría en Ingeniería Ambiental, Universidad Tecnológica Nacional, Facultad Regional de Buenos Aires, 2012: http://posgrado.frba.utn.edu.ar/investigacion/tesis/MIA-2012-Garcia.pdf [Consultado 22/04/2016].

${ }^{36}$ GONZÁLEZ, María y ROMÁN, Marcela, "Expansión agrícola en áreas extra pampeanas de la Argentina. Una 
La movilidad de capitales -de provincias como Buenos Aires, Santa Fe y Córdoba e incluso desde el extranjero- para el desarrollo de esta expansión productiva forma parte del denominado proceso de "pampeanización" que, como sostiene Walter Pengue, es un proceso social, económico y tecnológico que viene a realizar una importante transformación de aquellas regiones que "no son pampa", pero que pretenden que estas actúen básicamente como la pampa, a fuerza de inyección tecnológica y de capitales ${ }^{37}$.

Uno de los departamentos santiagueños que más se ha visto afectado por estos procesos es el de General Taboada. Este departamento comprende 604000 hectáreas y se estima que en el año 2012 alrededor de un 60\% de la superficie había sido afectada por procesos de desmonte. Sin embargo, una particularidad de esta zona es que la actividad de desmonte a favor de la producción agropecuaria se remonta a mediados de la década del setenta. Para esa década, un $22 \%$ de su superficie ya se encontraba desforestada. Entre los años 1987 y 1996, se desmontó un 24\% de la superficie forestada y, en el transcurso de 2001 y 2006, un 25\% más. De 2007 en adelante, la tasa de desmonte asume un valor de $7 \% 38$. En un principio, estas tierras fueron destinadas a la producción de algodón y sorgo, intercalando con la cría de ganado. Luego de la caída del precio del algodón hacia el año 1997, la orientación productiva se redirecciona hacia el cultivo de la soja.

En la siguiente imagen se puede observar el proceso de desmonte en el departamento de General Taboada.

Años de desmonte <1976 hasta 2012

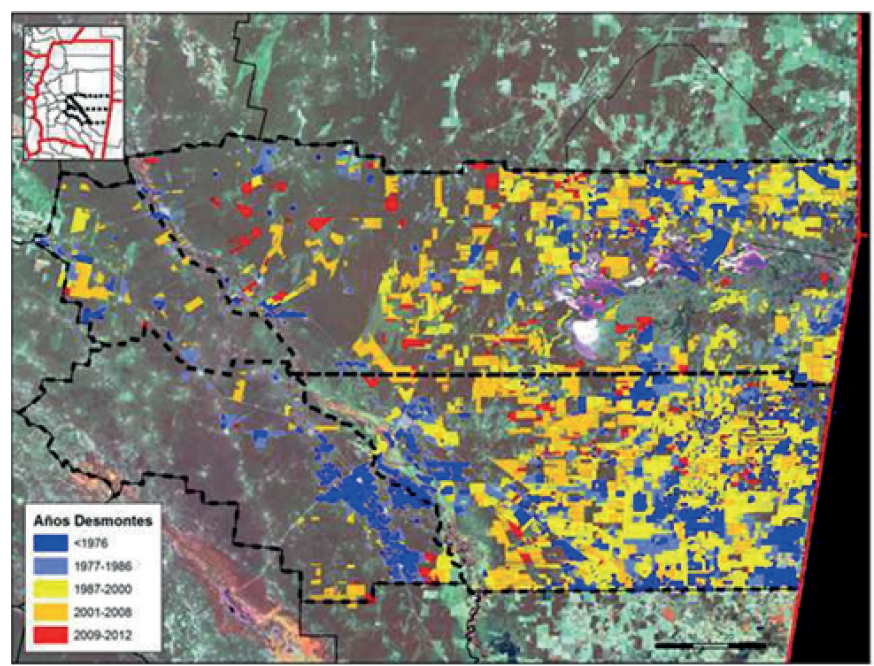

Elaboración: LART FAUBA en base a información procesada en el Laboratorio de Teledetección y SIG, INTA Salta.

mirada desde los actores sociales" en Cuadernos de Desarrollo Rural, Vol. 6, No 62, pp. 99-120.

37 PENGUE, Walter, "El desarrollo rural sostenible y los procesos de agriculturización, ganaderización y pampeanización en la llanura Chaco-Pampeana" en MORELLO, Jorge y RODRÍGUEZ, Andrea (eds.), El Chaco sin bosques: la Pampa o el desierto del futuro, Orientación Gráfica Editora, Buenos Aires, 2009, pp. 11-146.

${ }^{38}$ REDAF (Red Agroforestal Chaco Argentina), Bosques Nativos y Deforestación en la Provincia de Santiago del Estero, Informe para la Mesa Zonal del Ámbito de Tierras - MeZAT, Añatuya, 2012: http://redaf.org.ar/ wpcontent/uploads/2014/09/OK\%20informe_desmonte\%20Santiago\%20MEZAT_final09.12.13.pdf [Consultado 22/04/2016]. 
Entre las actividades laborales que han caracterizado a la zona se destaca, por lo tanto, una temprana inserción en la industria forestal. Este desarrollo de tipo extractivo se realizó sobre la base de la instalación de grandes empresas y una importante masa de trabajadores locales que se instalaron alrededor, para realizar las tareas. Una vez agotados estos procesos y a raíz de la disminución de la actividad obrajera en el área, se produjo una elevada desocupación de la mano de obra concentrada en su entorno. Si bien, por un lado, predominó la expulsión y migración de parte de la población inmersa en la actividad forestal, por el otro lado, se verificó el asentamiento definitivo de algunos trabajadores del obraje en sus antiguas parcelas residenciales de autosubsistencia, quienes con el tiempo se transformaron en campesino ${ }^{39}$ productores de algodón en unidades de producción minifundistas ${ }^{40}$.

En cuanto a las características poblacionales, históricamente la provincia de Santiago del Estero ha presentado elevados índices de pobreza como resultado de las condiciones de infraestructura desfavorables (viviendas y acceso a los servicios básicos), por pertenecer a un contexto productivo con escasas posibilidades de desarrollo económico, sobre todo, entre los pequeños productores con inserciones laborales precarias (baja estabilidad y temporarias) desarrolladas mayoritariamente fuera de la provincia.

En este contexto, las migraciones laborales agrarias han ocupado un rol fundamental como parte del sistema de producción y reproducción de las familias, sobre todo rurales. Se han escrito numerosos estudios dando cuenta de estos procesos, tanto desde la perspectiva de los mercados de trabajo (ciclos, características de los migrantes, condiciones de trabajo, remuneraciones, etc.) pero, también, se han focalizado en la interacción entre migración y familias rurales en aspectos tales como los aportes de la migración a la producción de los predios, la distribución de los ingresos dentro del ámbito familiar, las transformaciones en la dinámica de los hogares, entre los más relevantes ${ }^{41}$.

En este estudio, el abordaje metodológico es principalmente cualitativo y se basa en la realización y el análisis de entrevistas en profundidad. Se llevaron a cabo 30 entrevistas en profundidad a informantes clave (funcionarios públicos, docentes, líderes de movimientos sociales), pequeños productores, hijos/as y esposas de productores, trabajadores asalariados (migrantes y no migrantes), grandes productores y contratistas de maquinaria. El criterio para la selección de los/as entrevistados/as es conceptualmente intencionado, buscando examinar patrones de similitudes y diferencias en un número moderado de casos e intentando captar

${ }^{39}$ En este artículo, el concepto "campesino" hace referencia a los pequeños productores familiares de origen obrajero asentados en el territorio en estudio, tal como es descripto en el párrafo de referencia.

${ }^{40}$ GUAGLIONE, Adriana, Análisis y evaluación del impacto del modelo de desarrollo obrajero - forestal en el Chaco Santiagueño. El caso de Los Juríes, XXIII International Congress of the Latin American Studies Association, Washington, 2001.

${ }^{41}$ BENENCIA, Roberto. y FORNI, Floreal, "Asalariados y campesinos pobres: el recurso familiar y la reproducción de la mano de obra. Estudios de casos en la provincia de Santiago del estero" en Desarrollo Económico, Vol. 28, No. 110, 1988, pp. 245-279; MASTRANGELO, Andrea y DEMBROSI, Nicolás, "Trabajadores y campesinos. Análisis sobre la inserción social como trabajadores de pequeños propietarios de un paraje rural del sureste santiagueño" en MASTRANGELO, Andrea y TRPIN, Verónica (Comp.), Entre chacras y plantaciones. Trabajo rural y territorio en producciones que argentina exporta, CiCCuS, Buenos Aires, 2011, pp. 225-250; PAZ, Raúl y ZURITA, Carlos, "Disponibilidad laboral, diversidad productiva y ciclos de demanda de mano de obra. Un análisis del empleo rural en Santiago del Estero, Argentina" en Panaia Marta et. al. (Coords.), Trabajo y población en el Noroeste Argentino, La Colmena, Buenos Aires, 2000, pp. 167-196; QUARANTA, Germán y BLANCO, Mariela, "Formas..., op.cit., p. 129. 
y comprender su diversidad.

También se analizó complementariamente información secundaria proveniente de los censos nacionales agropecuarios y de población y vivienda para caracterizar la región y sus principales tendencias productivas y poblacionales.

\section{Múltiples movilidades en el departamento de General Taboada}

En el territorio del departamento de General Taboada se identifican diferentes tipos de movilidades que se expresan como un mapa de desplazamientos. Para cada una de estas movilidades se puede distinguir: el perfil de los sujetos sociales que se mueven, la dirección y motivo del traslado y los contextos que se conectan. Así, el departamento de General Taboada puede presentarse como el origen de la circulación, como el destino de la misma o funcionar como origen y destino de una movilidad rural-urbana.

Tal como se adelantó en la introducción, se analiza el comportamiento de las distintas movilidades en función de la distancia y la duración, el proceso selectivo de los grupos que circulan y las negociaciones que se ponen en juego para que produzca cada movilidad. A su vez, se presta atención a la interrelación entre las movilidades y a la redefinición de los individuos y los grupos que las transitan.

A continuación, se presentan los tres tipos de movilidades mencionados.

\subsection{Movilidad laboral}

Este tipo de movilidad se desarrolla desde el departamento de General Taboada hacia otras regiones en busca de empleos que permitan complementar los ingresos por "changas" 42 que se obtienen localmente durante el resto del año. Alrededor de 500 trabajadores del departamento se desplazan al centro del país o al "sur", como les gusta decir, para participar principalmente en la desflorada del maíz. Este circuito es uno de los más antiguos de la migración agrícola por temporada en Argentina y se realiza durante el verano. Los viajes se realizan en los meses de diciembre y enero y se recorren aproximadamente un promedio de 1000 kilómetros. Esta tarea resulta una oportunidad que no solo les permite complementar sus ingresos anuales sino también acrecentar su ingreso habitual, ya que los jornales que se pagan son superiores a los del mercado local.

El proceso selectivo que caracteriza a esta movilidad se materializa en la contratación de los trabajadores de sexo masculino y en edades centrales de trabajo - los de mayor edad suelen asumir el rol de "cabecilla" (jefe de cuadrilla). El tipo de trabajo que se realiza es colectivo; cada cuadrilla está conformada por un promedio de veinticinco personas y un cabecilla, y en los campos pueden convivir varias cuadrillas. Además de los requisitos demográficos, se exige al trabajador predisposición y fidelidad a las normas que rigen este trabajo y el "cabecilla" es el encargado de reunir a los integrantes de su cuadrilla.

Los trabajadores tienen escaso contacto con las empresas que los contratan debido a que utilizan los servicios de contratación de personal -como Manpower y Adecco-, que son

\footnotetext{
${ }^{42}$ Trabajo esporádico e informal que permite ganar ingresos mínimos.
} 
los encargados de contratar a las cuadrillas. Las sedes de estas empresas contratadoras se encuentran en Añatuya (departamento General Taboada), a ochenta kilómetros de la localidad de Los Juríes y en Colonia Dora (departamento Avellaneda), a cien kilómetros.

Generalmente, los trabajadores vuelven a ser contratados para las temporadas siguientes mediante la figura legal de "permanente discontinuo"43. Para asegurar la conformación de un grupo estable de trabajo, las empresas ponen en juego un sistema de premios y castigos para las cuadrillas. En el momento del trabajo, los migrantes son evaluados por medio de un sistema de puntajes en relación a limpieza y orden de los lugares de alojamiento, cumplimiento con el trabajo y ausencia de disturbios y conflictos. Las cuadrillas que obtienen los mejores puntajes son retribuidas con un extra de ingresos que recae en el "cabecilla".

Las negociaciones siempre se realizan antes del viaje, en el lugar de origen. El rol del "cabecilla" es fundamental en la organización de esta movilidad. Tener acceso a un cabecilla permite garantizarse una mejor inserción. Por un lado, actúa como reclutador de trabajadores. Por lo tanto, conocer al cabecilla facilita un puesto en la migración. Por otro lado, es el encargado de regular la demanda ya que en las épocas donde se requiere menos mano de obra, el cabecilla debe informar a los trabajadores sobre las posibilidades o no de realizar el viaje. A su vez, en el momento del trabajo, solo ellos tienen contacto con los encargados o ingenieros que controlan el trabajo.

Las denuncias ocurridas por malas condiciones de trabajo y los cambios en la legislación laboral para el trabajo asalariado agrario ${ }^{44}$ redefinieron gran parte de esta movilidad. Los trabajadores destacan la notable mejora en todo el proceso: transporte, alojamiento, calidad de las comidas, cumplimiento de la jornada de trabajo, desplazamientos dentro de los establecimientos, entre los más relevantes. Estas transformaciones impactaron en la extensión del viaje. Si bien el tiempo de esta actividad es de dos meses, la duración de la permanencia se ha acortado. Los trabajadores migrantes pueden realizar hasta tres o cuatro campañas durante ese período de tiempo; esto significa tener una estadía en destino de una semana hasta quince días, para luego regresar a su casa y permanecer una semana antes de volver a viajar.

\subsection{Movilidad por expulsión}

Esta es una forma de movilidad "forzada", aunque "cuando la opción del empleo no existe en casa, nunca puede considerarse completamente voluntaria"45 y presenta la particularidad de

${ }^{43}$ Cuando un trabajador temporario es contratado por un mismo empleador en más de una ocasión de manera consecutiva, para la realización de tareas de carácter cíclico o estacional, o por procesos temporales propios de la actividad agrícola, pecuaria, forestal o de las restantes actividades comprendidas será considerados a todos sus efectos como un trabajador "permanente discontinuo".

${ }^{44}$ En diciembre de 2011, se sanciona y promulga una nueva Ley de Régimen de Trabajo Agrario (Ley 26.727. En cuanto al trabajo temporario, determinado fundamentalmente por lo estacional o cíclico, y dentro del cual se encuentran los trabajadores migrantes, fija las condiciones generales que debe reunir el lugar en donde el trabajador desarrolle la tarea, los requisitos mínimos del alojamiento, las características de los servicios sanitarios, la obligación de la provisión de energía eléctrica, alimentos (en caso de que por la distancia al lugar de abastecimiento no lo pueda hacer el trabajador), agua potable, equipos de trabajo y elementos de seguridad que protejan y preserven la salud del trabajador, las condiciones que debe reunir el traslado de la mano de obra, etc.

${ }^{45}$ DAVIDSON, Alastair, "Ciudadanía y migración: ¿derechos para aquéllos sin pertenencia?" en Anales de la Cátedra 
desarrollarse en el interior de un mismo territorio (departamento de General Taboada). Los desplazamientos obedecen a la expulsión de sectores campesinos a raíz de la competencia por la tierra a partir del avance de la agricultura a gran escala en la región y, también, por la falta de oportunidades para el desarrollo económico de la pequeña producción.

Esta movilidad descansa sobre la selección del colectivo social "campesino", que se ve excluido del hábitat en el cual se encuentra radicado históricamente. La circulación puede ser del tipo rural-urbano (por desalojo y expulsión de su parcela) o rural-rural (como resultado de los procesos de reubicación de familias que atravesaron conflictos por la tierra). El incremento intercensal de las explotaciones de hasta las quinientas hectáreas (cerca del 30\%) explica los procesos de relocalización mostrando una movilidad rural-rural aunque no alcanza a la caída sufrida por las explotaciones sin límites definidos (60\%) (CNA, 1988 y 2002). El proceso de expansión sojera y de expulsión de población campesina de las explotaciones sin límites definidos condujo a una creciente urbanización. En el período 1991-2010, la población urbana del departamento se incrementó en 50\% y la rural dispersa disminuyó 14,2\% (CPA, 1991 y 2010).

Este tipo de movilidad se sostiene por las condiciones estructurales desiguales. Quienes reclaman la propiedad de la tierra son figuras sociales "ausentistas", aunque los que impulsan la movilidad en el territorio son agentes intermediarios, generalmente abogados, apoyados en gran parte por el poder político y judicial. A su vez, la crisis del algodón, principal cultivo de este tipo de productores, también impulsó el abandono de la actividad predial y el cambio residencial. En relación a esto último, es importante señalar la existencia de un mercado de compra y venta de pequeñas superficies de tierras. Algunos productores locales mejor posicionados económicamente, compran o alquilan tierra para poder incrementar el tamaño de producción de sus explotaciones.

La movilidad por expulsión implica una fuerte transformación de la identidad del grupo social. Existen familias tradicionalmente rurales residiendo en la localidad de Los Juríes pero que aún mantienen su parcela, de menor tamaño a partir de que fueron reubicados. Una de las consecuencias de este proceso es la división de la familia, ya que parte de la misma queda viviendo en el predio (hermanos, padres del jefe u otro familiar) con producciones para el autoconsumo y empleos eventuales extraprediales y otros se trasladan a la localidad de Los Juríes.

Las situaciones de reubicación también llevaron, en muchas ocasiones, al abandono de la actividad en el establecimiento. El modelo de desarrollo rural imperante en la zona, el cultivo de soja, resulta inaccesible para este grupo social debido a que factores tales como la escala de producción, el acceso a la tecnología y los bajos niveles de capitalización que impiden el acceso a este modelo.

Esta movilidad es permanente y habitual. Tanto los que viven en los predios reubicados como los que cambiaron de residencia, mantienen un fuerte arraigo a la vida y cultura campesina. Junto a la añoranza de la "época del algodón" se fortalece el arraigo en la

Francisco Suárez, No 37, 2003, pp. 35-55. 
valoración de la vida rural frente a la urbana. Los cambios en las identidades son más lentos que los cambios del entorno. Las situaciones de tenencia precaria de las tierras se encuentran latentes - a pesar de los largos años de conflictos- y actualmente no se visualizan opciones para su solución.

Este tipo de movilidad tiene un doble impacto en el territorio. Por un lado, el desplazamiento de aquellos que han tenido que abandonar sus tierras $y$, por el otro, los procesos de urbanización o relocalización de esa población expulsada. De esta forma, la expulsión y la relocalización son las dos caras de una misma movilidad.

\subsection{Movilidad empresarial}

Como ya se ha mencionado, la agricultura a gran escala se posiciona de forma generalizada en vastos espacios rurales de la provincia. Un contexto de precios internacionales favorables, la introducción de un modelo productivo efectivo en la relación costo-beneficio y la falta de políticas para regular la actividad favorecieron el avance de la frontera agropecuaria.

A partir del año 2002, cuando Argentina atraviesa la devaluación del peso y, por otro lado, se incrementan los precios internacionales de los productos agropecuarios, se establece definitivamente el modelo productivo que caracterizará a la región pampeana hasta la actualidad y que, con el transcurso del tiempo, se empezará a aplicar en regiones agroecológicas más frágiles y sin tradición en este tipo de producciones.

Se identifica a este proceso como el traslado del modelo productivo de la región pampeana argentina, históricamente dedicada a la producción de cereales y oleaginosas, hacia áreas periféricas del país ${ }^{46}$. Este desplazamiento inaugura una nueva vía de circulación de tipo "empresarial". La resultante de la inversión del capital financiero en el cultivo fue la expansión hacia otros territorios dónde se desplazaron superficies con pastizales, bosques y montes espontáneos y esto ocurrió, fundamentalmente, en las provincias de Santiago del Estero, Salta, Chaco y Formosa.

Una de las características de este modelo es la organización del proceso de producción $y$, sobre todo, el del trabajo a través de empresas prestadoras de servicios. La prestación más difundida es el servicio de maquinaria agrícola para tareas de siembra, mantenimiento de cultivos y cosecha. Los contratistas de maquinarias tienen un rol destacado en el nuevo paradigma de producción, por ser los actores clave en la incorporación y difusión tecnológica. En general, se reconoce a este sector como empresarios innovadores.

Los altos desembolsos de dinero para la inversión en maquinarias demandan la necesidad de amortizar los costos del capital. Las oportunidades en las diferencias estacionales de las producciones hicieron que el traslado hacia nuevas zonas resultara una opción de trabajo ${ }^{47}$.

Es así que en épocas del año muy puntuales, llegan a Los Juríes (departamento de

46 GORENSTEIN, Silvia y ORTÍZ, Ricardo, "La tierra.... op.cit., p. 9.

47 Santiago del Estero, al pertenecer a una región de climas más cálidos, con precipitaciones más usuales durante el invierno, hace que los períodos de siembra sean más tempranos que en la región pampeana y, por ende, de las tareas vinculadas a la cosecha. 
General Taboada) grupos de contratistas para trabajar en los campos agrícolas, en general de grandes extensiones. La duración de la estadía que está supeditada a las condiciones climáticas (lluvias), ronda los veinte-treinta días y, en época de cosecha, puede incrementarse.

El proceso selectivo de esta movilidad es un tipo de contratista que maneja tecnología de gran escala (sembradoras y cosechadoras de gran tamaño), con un origen pampeano en donde también presta servicios. Como los propietarios de la tierra tienen su residencia fuera de Los Juríes, los arreglos y negociaciones se llevan a cabo en el punto de partida del desplazamiento. El viaje se realiza con todas las maquinarias y con el personal que las opera (cuadrillas de tres o cuatro trabajadores). Junto con las maquinarias se movilizan los módulos habitacionales en los que viven los empleados. Los contratistas se alojan en las habitaciones de los hoteles de la localidad y los trabajadores en el campo.

La movilidad empresarial se trata, fundamentalmente, de la movilidad del capital cristalizado en los equipos de maquinaria agrícola. Los requerimientos de trabajo asociados a esta actividad son notablemente bajos: se estima un promedio de dos horas/hombre/año por hectárea cultivada con soja ${ }^{48}$. Así, la presencia de trabajadores (principalmente, maquinistas) se presenta supeditada a la movilidad del capital.

Esta movilidad ha generado algunas pocas oportunidades de empleo en el área local; se trata de jóvenes que han conseguido insertarse en tareas de organización y control de las actividades que se realizan en los establecimientos empresariales. Apoyan logísticamente a los contratistas (compra de combustibles, herbicidas, alimentos, etc.) y controlan el trabajo y los desplazamientos de los mismos entre los lotes. Estos empleos son formales y permanentes. Otros empleos de carácter precario son ocupados por trabajadores rurales, como la limpieza de malezas en campos, las carpidas post cosechas y el acarreo de bolsas. Las desventajas socioeconómicas del contexto son aprovechadas por esta movilidad para reproducir las condiciones de contratación laboral imperantes en la zona: trabajo no registrado, bajas remuneraciones e inestabilidad de la ocupación.

Al analizar la interrelación entre las diferentes movilidades, lo primero que se observa es que los integrantes de la migración laboral se pueden solapar con los que forman parte de la movilidad por expulsión. El perfil social es similar y su hogar de residencia se encuentra en el departamento de General Taboada. Sin embargo, mientras los primeros se mueven "voluntariamente" para complementar ingresos, los segundos fueron forzados a dejar su lugar de residencia, ya sea porque fueron expulsados de sus predios y migraron a la localidad o porque fueron relocalizados en parcelas más pequeñas. La movilidad empresarial, en cambio, si bien incluye a los trabajadores y contratistas, también incorpora la movilidad de producciones y capitales.

Por otra parte, los que se movilizan laboralmente o por expulsión también pueden participar como trabajadores ocasionales en las producciones de la movilidad empresarial para realizar tareas como la limpieza de malezas en campo, carpidas, carga de bolsas en

48 NEIMAN, Guillermo, Estudio sobre la demanda de trabajo en el agro argentino, Editorial Ciccus, Buenos Aires, 2000 , p. 323. 
época de cosecha, entre las más frecuentes. Las contrataciones revisten una alta precariedad e incertidumbre. Son trabajos por tiempos acotados, no registrados y retribuidos por jornal. No existen márgenes de negociación por salarios o jornadas de trabajo. Los trabajadores ingresan y salen continuamente de estos empleos sin tener mayor expectativa que obtener un ingreso ocasional en ausencia de la movilidad laboral. En un caso similar, Bares muestra que, en la Patagonia, muchos jóvenes que provienen de campos con una "estructura productiva reducida" y con infraestructuras prediales limitadas, terminaron trabajando para las estancias de la familia Benetton ${ }^{49}$.

La movilidad por expulsión involucra a todo el grupo familiar, que la mayoría de las veces se traslada completo aunque en ocasiones la familia se divide: una parte queda en el predio relocalizado y otra en ámbitos urbanos. Cuando una parte de la familia se muda a ámbitos urbanos se establece un "doble domicilio"50 rural y urbano para poder acceder a servicios educativos, de salud, etc. Sin perder su residencia familiar rural; Luis Camarero y Jesús Oliva desarrollan también el concepto de bi-residencialidad en relación a esos grupos familiares que alternan residencias en asentamientos rurales y urbanos ${ }^{51}$. A diferencia de este tipo de movilidad, la movilidad laboral y la empresarial son preponderantemente masculinas y la familia sigue residiendo en el hogar habitual mientras que el o los hombres son los que se movilizan.

\section{Conclusiones}

Los mapas de desplazamientos originados a partir de la combinación de una "multiplicidad de movilidades" 52 conforman regiones sociales que se caracterizan por la interdependencia de los flujos, el intercambio de mano de obra, la movilización del capital y la producción por expansión de la frontera agropecuaria, y los cambios residenciales de la población local por los desalojos y la reubicación de parcelas.

El desarrollo de estas regiones sociales se basa en la combinación de la agencia humana y la no humana en su articulación con las estructuras territoriales. Así, las cadenas globales de agro-alimentos se articulan con los territorios productivos en sistemas que integran proveedores de insumos (tecnología, semillas, etc.), migración de trabajadores (que llevan a cabo la cosecha), productores locales, infraestructura y sistema de transporte (flete) ${ }^{53}$.

En un estudio sobre innovaciones sociales y desarrollo territorial, Frank Moulaert y Jacques Nussbaumer asocian el empleo del concepto de "región social" con la necesidad de considerar, desde las políticas nacionales, las dinámicas institucionales locales, las relaciones (de poder) comunitarias existentes y los vínculos con redes supralocales que proporcionan un

\footnotetext{
${ }^{49}$ BARÉS, Aymará, "Comunicación, movilidades y espacialidades. desplazamientos y trayectorias de jóvenes de Ñorquinco y Cushamen en la región de la patagonia argentina" en Revista Latinoamericana de Estudios Rurales, Vol. 1, No 1, 2016, pp. 105-134.

${ }^{50}$ Ibídem, p. 119.

${ }^{51}$ CAMARERO, Luis y OLIVA, Jesús, "Understanding Rural Change: Mobilities, Diversities and Hybridizations" en Sociálnístudia / Social Studies, No 2, 2016, pp. 93-112.

52 SHELLER, Mimi y URRY, John, "The new mobilities paradigm" en Environment and planning, Vol. 38, 2006, pp. 207-226.

${ }^{53}$ CAMARERO, Luis y OLIVA, Jesus, "Understanding..., op.cit., p. 94.
} 
knowhow específico ${ }^{54}$. En esta misma línea, Doreen Massey se opone a entender la globalización como una relación dicotómica entre lo global y lo local y muestra que las economías locales experimentan la necesidad de estar abiertas a las inversiones internacionales, pero después ven aparecer los problemas del control externo y de la desintegración de vínculos que antes conformaban una economía local más coherente ${ }^{55}$.

Asimismo, en David Harvey, se podría considerar la conformación de una región cuando las escalas adquieren cierta "coherencia estructural" y el capital se "fija", de forma momentánea, para poder producir y seguir acumulado. En el caso estudiado, la necesidad de contar con tierra con determinadas características ${ }^{56}$ como factor de producción, refuerza los "anclajes espaciales" del capital y, por lo tanto, la conformación de regiones ${ }^{57}$.

Alain Tarrius, por su parte, produce una ruptura con los conceptos de territorio, escala y región, tal como se los considera, proponiendo el concepto de "territorio circulatorio", donde la socialización de los espacios está supeditada a las lógicas de la movilidad ${ }^{58}$.

Además, si bien los procesos de globalización diferencian regiones "de producción" de aquellas "de consumo", al mismo tiempo las ligan con una lógica de profunda interdependencia, lo cual pone en cuestión la idea del rol subordinado de las áreas rurales en los ciclos de acumulación. $Y$ en este contexto, los problemas que enfrentan las poblaciones rurales no son muy distintos de los problemas sociales y espaciales que enfrenta la sociedad en su conjunto ${ }^{59}$.

Aquí se entiende a la región social dentro de los procesos de movilidad como la construcción de territorios cuyas ventajas comparativas se inscriben en relaciones sociales más que en atributos del carácter natural de los espacios. En los tres tipos de movilidad analizados se destacaron los diferentes contextos sociales que conectan y las nuevas formas de organización social que se imprimen en los grupos sociales afectados. La organización de la región define nuevos ordenamientos para los individuos, en lo que respecta a la definición de su rol como productor o asalariado, por ejemplo los pequeños productores que se desplazan se ven obligados a una readecuación a la residencia y a un estilo de vida diferente, donde las familias deben adaptar sus estrategias de reproducción y su posicionamiento en la escala social según las oportunidades de movilidad que puedan ofrecer sus miembros.

La figura que se presenta a continuación muestra los vínculos entre las diferentes formas de movilidad, en un contexto de globalización, reestructuración productiva e inserción en cadenas agroalimentarias que produce regiones sociales, identidades y una eclosión de

54 MOULAERT, Frank y NUSSBAUMER, Jacques, "The social region. Beyond the territorial dynamics of the learning economy" en European urban and regional studies, No 12, 2005, pp. 45-64.

55 MASSEY, Doreen, "Geographies of responsibility" en GeografiskaAnnaler B, No 86, 2004, pp. 5-18.

${ }^{56}$ Estas tierras, además de ser aptas para la producción de cereales y oleaginosas, estaban ocupadas por población campesina con problemas en la titulación de la propiedad. Esta situación resultó atractiva para el capital ya que la apropiación de la tierra, más o menos violenta según los casos, se vio facilitada.

57 HARVEY, David, Spaces of Hope, Edimburgh University Press, Escocia, 2000, p. 293.

58 TARRIUS, Alain, "Leer, describir..., op.cit., p. 42.

${ }^{59}$ Ibídem, p. 96; HERVIEU, Bertrand, Los campos del futuro, Serie Estudios No 118, Ministerio de Agricultura, Pesca y Alimentación, España, 1996, p. 195. 
movilidades que, a su vez, forman parte e impulsan dichos procesos de globalización.

Figura 1: Los vínculos entre las formas de movilidad en el contexto de globalización

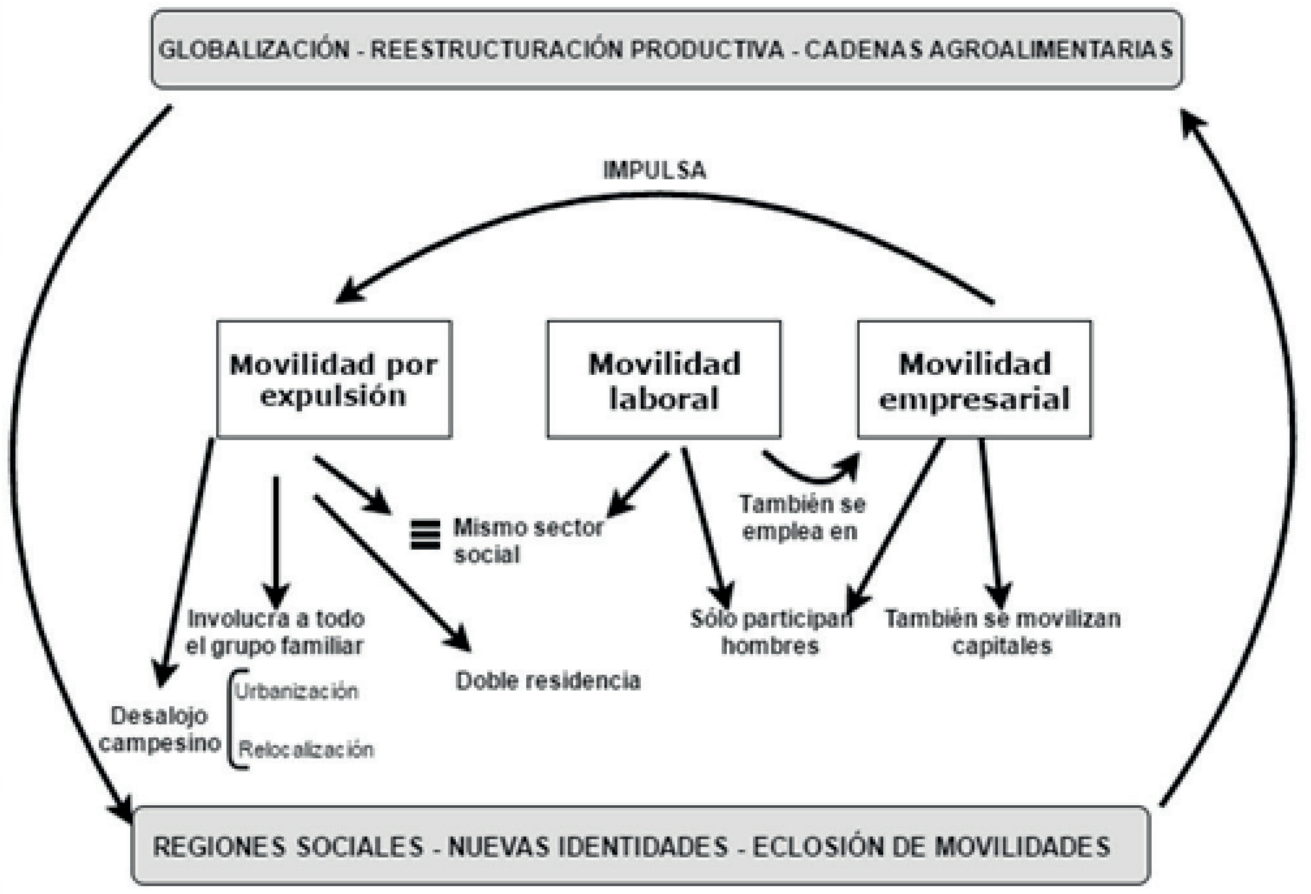

La participación en las distintas formas de movilidad no se encuentra ajena a los impactos en la demografía de las familias asociados a: su nuclearización para la residencia (con fuertes vínculos a la red familiar por la doble residencia), la división por género para las movilidades laboral y empresarial, la asalarización de sus integrantes en empleos precarios en las nuevas producciones (a partir de la llegada de nuevos mercados de trabajo) y la creciente urbanización (luego de los desalojos y ventas de los predios).

Estos procesos de adaptación al nuevo contexto de integración global de las regiones inmersas en el régimen corporativo de producción de alimentos son también acompañados de procesos de "reterritorialización", producto de la formación de nuevos perfiles sociales por el entrecruzamiento de las simultáneas identidades de pertenencia. Entre estas múltiples identidades se reconoce: la identidad "campesina"60 de aquellos que se asentaron en las áreas rurales de la región atraídos por el trabajo que ofrecía el obraje forestal; la de los que se organizan con el sistema de "cabecillas" para movilizarse a otros cultivos/regiones demandantes de mano de obra; la de quienes se mudaron recientemente del campo a la localidad; la de aquellos que solo permanecen en el departamento durante la cosecha del cultivo de soja (productores, contratistas y trabajadores); etc.

La interrelación entre las diferentes movilidades lleva también al cruce de estas identidades y, de esta forma, a la formación de nuevas identidades o "subjetividades móviles",

${ }^{60}$ Con el concepto "identidad campesina" nos referimos a un modo de vida ligado al reconocimiento del espacio rural como lugar de residencia y de la pequeña actividad agropecuaria como práctica cotidiana. 
en tanto discursos y prácticas que generan la movilidad, pero también estabilidad ${ }^{61}$. Así como también, el territorio, además de producir identidad, produce alteridad, lo diferente, que se encuentra en un mestizaje que remueve los lugares comunes de la identidad ${ }^{62}$.

Así, frente a las mayores interdependencias que se mantienen en el funcionamiento de un sistema global, el concepto de región social anclado en la movilidad inaugura una nueva perspectiva para interpretar y analizar la estructuración social, permitiendo realizar el salto entre lo local y lo global, acercando las distancias entre regiones políticas, económicas, productivas y culturales.

\section{Bibliografía}

ALBERTI, Alfonsina, BARDOMÁS, Silvia y SCHIAVONI, Gabriela, "Temporalidad cíclica y territorio móvil. Los trabajadores forestales del nordeste argentino" en Estudios del Trabajo ASET, No 48, 2014, pp. 5-28.

ALFARO, María Inés, "Experiencias de organización campesina en Santiago del Estero. Reflexiones en torno a las acciones colectivas" en BENENCIA Roberto y FLOOD, Carlos (Comp.), ONGs y Estado. Experiencias de organización rural en Argentina, La Colmena, Buenos Aires, 2002, pp. 159-175.

ARANGO, Joaquín, "La explicación teórica de las migraciones: luz y sombra" en Migración y Desarrollo, $N^{\circ} 1,2003$, pp. 3-31.

BARBETTA, Pablo, "En los bordes de lo jurídico: campesinos y justicia en Santiago del Estero" en Cuadernos de Antropología Social, No 32, 2010, pp. 121-146.

BARÉS, Aymará, "Comunicación, movilidades y espacialidades. Desplazamientos y trayectorias de jóvenes de Ñorquinco y Cushamen en la región de la Patagonia argentina" en Revista Latinoamericana de Estudios Rurales, Vol. 1, No 1, 2016, pp. 105-134.

BLANCO, Mariela y CARRIZO, Lila, "Procesos sociales complejos de interacción e inserción territorial. La mano de obra migrante transitoria en Pomán, Catamarca" en Aportes Científicos para las Humanidades, 2012, pp. 1-12.

BORRAS, Saturnino, FRANCO, Jennifer, KEY, Cristóbal, SPOOR, Max, El acaparamiento de tierras en América Latina y el Caribe visto desde una perspectiva internacional más amplia, Borrador, FAO, Roma, 2011: http://www.fao.org/fileadmin/user_upload/rlc/eventos/229269/borras.pdf [Consultado 11/07/2016].

CAMARERO, Luis y OLIVA, Jesús, "Understanding Rural Change: Mobilities, Diversities and Hybridizations" en Sociálnístudia / Social Studies, No 2, 2016, pp. 93-112.

CORTES, Genevieve, "Migraciones, construcciones trasnacionales y prácticas de circulación. Un enfoque desde el territorio" en Párrafos Geográficos, Vol. 8, No 1, 2009, pp. 35-53.

COSTANTINO, Agustina, "El capital extranjero y el acaparamiento de tierras: conflictos sociales y acumulación por desposesión en Argentina" en Revista Estudios Sociales, № 55, enero-marzo, 2016, pp. 137-149.

DAVIDSON, Alastair, "Ciudadanía y migración: ¿derechos para aquéllos sin pertenencia?" en Anales de la Cátedra Francisco Suárez, No 37, 2003, pp. 35-55.

de DIOS, Rubén y WILLIAMS, Jorge, "Sistemas productivos y organización campesina. El caso de Los Juríes" en ÁLVAREZ, Ramón, Sistemas productivos campesinos en Santiago del Estero. Organizaciones y unidades de producción. Uso de tipologías en los procesos de reconversión, Barco Editó, Santiago del Estero, 1998, p. 191.

DELAUNY, Daniel, "Relaciones entre pobreza, migración y movilidad: dimensiones territorial y contextual" en Notas de Población - CEPAL, No 84, Chile, 2007, pp. 87-130.

del REY, Alberto y QUESNEL, André, Migración interna y migración internacional en las estrategias familiares de reproducción. El caso de las poblaciones rurales del sur del estado de Veracrúz, México, I Congresso da Associação Latino Americana de População, ALAP, Caxambú, Brasil, 18 - 20 de Septiembre de 2004: http://www.alapop.org/alap/files/docs/congreso2004/ alap2004_225.pdf [Consultado 11/07/2016].

DESALVO, María Agustina, "El MOCASE: orígenes, consolidación y fractura del movimiento campesino de Santiago del Estero" en Astrolabio Nueva Época, No 12, 2014, pp. 271-300.

${ }^{61}$ SCHELLER, Mimi y URRY, John, "The new..., op.cit., p. 109.

62 TARRIUS, Alain, "Leer, describir..., op.cit., p. 56. 
GARCIA, Mabel, La influencia del tipo de productor en la sustentabilidad de los cultivos. El caso de la soja en Santiago del Estero, TESIS de Maestría en Ingeniería Ambiental, Universidad Tecnológica Nacional, Facultad Regional de Buenos Aires, 2012: http://posgrado.frba.utn.edu. ar/investigacion/tesis/MIA-2012-Garcia.pdf [Consultado 25/06/2016].

GIANCOLA, Silvana, SALVADOR, María, COVACEVICH, Melina e ITURRIOZ, Gabriela, Análisis de la cadena de soja en la Argentina, Estudios Socioeconómicos de los sistemas Agroalimentarios y Agroindustriales, Estudios Socioeconómicos de los Sistemas Agroalimentarios y Agroindustriales N०3, INTA, 2009.

GONZÁLEZ, María y ROMÁN, Marcela, "Expansión agrícola en áreas extrapampeanas de la Argentina. Una mirada desde los actores sociales" en Cuadernos de Desarrollo Rural, Vol. 6, No 62, pp. 99-120.

GONZÁLEZ, Sara, "La geografía escalar del capitalismo actual" en Pegada, Vol. 6, №1, 2005, pp. 91112.

GORENSTEIN, Silvia y ORTÍZ, Ricardo, "La tierra en disputa. Agricultura, acumulación y territorio en la Argentina reciente" en Revista Latinoamericana de Estudios Rurales, Vol. 1, No 2, 2016, pp. $1-26$.

GUAGLIONE, Adriana, Análisis y evaluación del impacto del modelo de desarrollo obrajero - forestal en el Chaco Santiagueño. El caso de Los Juríes, XXIII International Congress of the Latin American Studies Association, Washington, 2001.

HANSON, Susan, "Perspectives on the geographic stability and mobility of people in cities" en PNAS Proceedings of the National Academy of Sciences of the United States of America, Vol. 102, No 43, 2005: http://www.pnas.org/cgi/doi/10.1073/pnas.0507309102 [Consultado 20/3/2016].

HARVEY, David, Spaces of Hope, Edimburgh University Press, Escocia, 2000, p. 293.

HARVEY, David, "El 'nuevo' imperialismo: acumulación por desposesión", Socialist register 2004 - CLACSO, Buenos Aires, 2005, pp. 99-129: http://biblioteca.clacso.org.ar/clacso/se/20130702120830/ harvey.pdf [Consultado 29/05/2017].

HERVIEU, Bertrand, Los campos del futuro, Serie Estudios, No 118, Ministerio de Agricultura, Pesca y Alimentación, España, 1996, p. 195.

INDEC, Censos nacionales agropecuarios, 1988 y 2002.

INDEC, Censos nacionales de población y vivienda, 2001 y 2010.

LARA FLORES, Sara, "Características de las migraciones rurales hortícolas en el noroeste de México" en Revista Latinoamericana de Estudios del Trabajo, No 12, 2000, pp. 71-88.

LARA FLORES, Sara, Control del espacio y territorialidad en las migraciones rurales. Un empleo en el caso de México, VII Congreso Latinoamericano en Sociología Rural Quito, Ecuador, 2006.

LARA FLORES, Sara, "Los territorios migratorios como espacios de articulación de migraciones nacionales e internacionales. Cuatro casos del contexto mexicano" en Política y Sociedad, Vol. 49, No 12, 2012, pp. 89-102.

LEÓNARD, Eric, del REY, Alberto y QUESNEL, André, "De la comunidad territorial al archipiélago familiar. Movilidad, contractualización de las relaciones intergeneracionales y desarrollo local en el sur del estado de Veracrúz" en Estudios Sociológicos, Vol. 23, No 3, México, 2004, p. 557.

MASSEY, Doreen, "Geographies of responsibility" en Geografiska Annaler B, No 86, 2004, pp. 5-18.

MÓDENES, Juan, Movilidad espacial: uso temporal del territorio y poblaciones, X Congreso de la Población Española: Migraciones, movilidad y territorio, Pamplona, 29 de junio - 1 de julio de 2006: http://www.ced.uab.es/publicacions/PapersPDF/Text311.pdf [Consultado 11/04/2016].

MORAES, Natalia, GADEA, Elena, PEDREÑO CÁNOVAS, Andrés y de CASTRO, Carlos, "Enclaves globales agrícolas y migraciones de trabajo: convergencias globales y regulaciones transnacionales" en Política y Sociedad, N 49, 2012, pp. 13-34.

MOULAERT, Frank y NUSSBAUMER, Jacques, "The social region. Beyond the territorial dynamics of the learning economy" en European urban and regional studies, No 12, 2005, pp. 45-64.

NEIMAN, Guillermo, Estudio sobre la demanda de trabajo en el agro argentino, Editorial Ciccus, Buenos Aires, 2000, p. 323.

PARUELO, José, OESTERHELD, Martín, del PINO, Federico, GUERSCHMAN, Pablo, CARIDE, Constanza, VERÓN, Santiago, AROCENA, María, PIÑEIRO, Gervasio, VASSALLO, María, VOLANTE, José, PORFIRIO, Lucia y BALDI, Germán, Patrones espaciales y temporales de la expansión de Soja en Argentina. Relación con factores socio-económicos y ambientales, Laboratorio de Análisis Regional y Teledetección Facultad de Agronomía, Universidad de Buenos Aires, 2004.

PAZ, Raúl Y JARA, Cristián, "Estructura agraria en Santiago del Estero: el proceso de territorialización de las explotaciones campesinas sin límites definidos y su tensión frente al avance del capitalismo agrario" en Estudios Rurales, No 4, 2014, pp. 81-99.

PENGUE, Walter, "El desarrollo rural sostenible y los procesos de agriculturización, ganaderización y pampeanización en la Ilanura Chaco-Pampeana" en MORELLO, Jorge y RODRÍGUEZ, Andrea (eds.), El Chaco sin bosques: la Pampa o el desierto del futuro, Orientación Gráfica Editora, Buenos Aires, 2009, pp. 11-146. 
PEDREÑO CÁNOVAS, Andrés, Del jornalero agrícola al obrero de las factorías vegetales, M.A.P.A., Madrid, 1999, p. 374.

QUARANTA, Germán y BLANCO, Mariela, "Formas actuales de circulación y conformación de patrones migratorios de hogares rurales en la provincia de Santiago del Estero, Argentina" en RURIS Revista do Centro de Estudos Rurais, Vol. 6, N01, 2012, pp. 127-158.

QUESNEL, André, "El concepto de archipiélago: una aproximación al estudio de la movilidad de la población y a la construcción de lugares y espacios de vida" en LARA FLORES, Sara (coord.), Migraciones de trabajo y movilidad territorial, Editorial Purrúa, México, 2010, pp. 19-46.

REDAF (Red Agroforestal Chaco Argentina), Bosques Nativos y Deforestación en la Provincia de Santiago del Estero, Informe para la Mesa Zonal del Ámbito de Tierras - MeZAT, Añatuya, 2012: http:// redaf.org.ar/wpcontent/uploads/2014/09/OK\%20informe_desmonte\%20Santiago\%20MEZAT_ final09.12.13.pdf [Consultado 22/04/2016].

TAURRIUS, Alain, "Las circulaciones migratorias: conveniencia de la noción de territorio circulatorio. Los nuevos hábitos de la identidad" en Relaciones, Vol. 21, No 83, 2000 pp. 38-66.

SÁNCHEZ SALDAÑA, Kim, "Un enfoque multidimensional sobre los intermediarios laborales en el medio agrícola" en Política y Sociedad, Vol. 49, No 1, 2012, pp. 73-88.

SEGURA, Pedro, PEDREÑO CÁNOVAS, Andrés y de JUANA, Susana, "Configurando la Región Murciana para las frutas y hortalizas: racionalización productiva, agricultura salarial y nueva estructura social del trabajo jornalero" en Áreas, Vol. 22, 2002, pp. 71-94.

SHELLER, Mimi y URRY, John, "The new mobilities paradigm" en Environment and planning, Vol. 38, 2006, pp. 207-226. 


\section{RELACIONES INTERNACIONALES}

Revista académica cuatrimestral de publicación electrónica Grupo de Estudios de Relaciones Internacionales (GERI) Universidad Autónoma de Madrid, España

www.relacionesinternacionales.info

ISSN 1699 - 3950

ff facebook.com/RelacionesInternacionales

twitter.com/RRInternacional 